\title{
Implementation of a Student-Developed, Service-Based Internship for Pharmacy Students
}

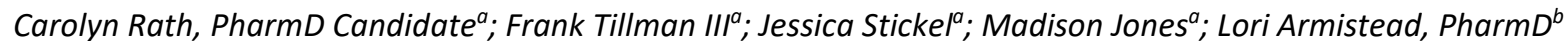

${ }^{a}$ University of North Carolina Eshelman School of Pharmacy; ${ }^{b}$ Center for Medication Optimization, University of North Carolina Eshelman School of Pharmacy

\begin{abstract}
Purpose: This article describes the development, implementation, and impact of a student-created pharmacy internship program with aspects of service-learning, professional development, and ambulatory care pharmacy practice.

Program Description: As the pharmacy profession continues to evolve, pharmacy internships present valuable opportunities for student pharmacists to explore career pathways and develop personal and professional skills. While internships in clinical and industry settings support interns' professional development, service-based internships provide additional benefits to student pharmacists by promoting cultural awareness, community engagement, and commitment to serving underserved patients. Student leaders from the Student Health Action Coalition (SHAC) at the University of North Carolina Eshelman School of Pharmacy created a service-learning, ambulatory carefocused pharmacy internship for fellow student pharmacists. Two rising third-year students were selected to participate in the internship in the summer of 2018. Over the two-month program, the interns participated in various program components including direct patient care activities, faculty-led workshops and topic discussions, and quality improvement projects. In addition to supporting the interns' academic and professional growth, this program also furthered the mission of SHAC to promote positive health outcomes for underserved populations.

Summary: The SHAC Ambulatory Care in Underserved Populations Internship represents an innovative initiative by pharmacy student leaders to develop a service-focused internship for fellow student pharmacists. Participation in the internship provides unique opportunities not often available in conventional pharmacy curricula, including engagement with underserved patient populations and exploration of strategies to mitigate health disparities. Crafted by students for fellow students, this internship provides opportunities for personal and professional growth for both student developers and interns to carry into their future pharmacy careers.
\end{abstract}

Key Words: internship, student pharmacists, ambulatory care, service-learning, underserved

\section{Background}

As career opportunities for pharmacists continue to expand and evolve, internships have become an increasingly important component of pharmacy education. Internships not only present opportunities to develop clinical, professional, and communication skills, but also provide exposure to diverse pharmacy practice settings and different approaches to pharmacy practice. There are currently a wide variety of internships available for pharmacy students. Some hospitalbased internships provide multi-faceted experiences within distributional operations, clinical care, and health system pharmacy administration. ${ }^{1-3}$

Internship programs with pharmaceutical companies and government agencies are also available for students interested in careers in industry and regulatory affairs, respectively. ${ }^{4-7}$ The advent of internships in specialty, community, and ambulatory care pharmacy have expanded the horizons for students interested in these fields. ${ }^{8-11}$

Evaluations of existing pharmacy internships have suggested that these programs play an instrumental role in shaping

Corresponding author: Carolyn Rath, PharmD Candidate University of North Carolina Eshelman School of Pharmacy Email: cgr8@email.unc.edu students' career pathways. For example, the recent restructuring of a community pharmacy internship at a major supermarket chain enhanced students' learning opportunities through increased interactions with both patients and pharmacy managers. ${ }^{9}$ By allowing participants to explore aspects beyond dispensing medications, this program helped students build the clinical and business management skills required to become successful community pharmacists. ${ }^{9}$ Additionally, since retention of student pharmacists after graduation is often a stated goal of internships, these experiences can directly impact students' career trajectories. ${ }^{3}$ For example, four students who completed an internship at the University of Pittsburgh Medical Center between 2004 and 2009 were ultimately hired as hospital pharmacists at the site. ${ }^{3}$ Regardless of long-term job prospects at a given institution, students are encouraged to pursue internships to demonstrate their commitment to a given career pathway and gain valuable experience. ${ }^{8}$

In addition to preparing student pharmacists for future careers, internships provide benefits for organizations and community members. For example, pharmacy interns at the North Carolina Cancer Hospital have enhanced the efficiency of distributional operations and allowed for significant cost savings due to the decreased allotment of overtime pay to pharmacy technicians. ${ }^{1}$ Student interns can also positively contribute to the patient care processes and efforts of an organization. Through the aforementioned community pharmacy internship, students 
conducted approximately 2500 health screenings and 500 medication counseling sessions over 10 weeks, demonstrating the value of the internship in promoting patient care efforts. ${ }^{9}$ Beyond positively impacting the organizations and communities they serve, interns themselves can reap additional benefits through these experiences, including personal and professional growth, formation of mentoring relationships, and development of leadership skills. ${ }^{2}$

While pharmacy internships in clinical and industry settings promote career exploration and professional development, service-based internships add a community engagement component that may be missing from these experiences. In recent decades, rising interest in "service-learning" within health professional schools has driven curricular changes that emphasize improving access to health care and resources, especially for underserved populations. ${ }^{12,13}$ The goals of servicelearning programs include enhancing relationships between academic institutions and underserved communities and allowing students to apply classroom knowledge through service. ${ }^{12,14}$ In the early 2000s, the American Association of Colleges of Pharmacy (AACP) emphasized the potential for service-learning to instill a spirit of community engagement and enhance students' educational experiences. ${ }^{15}$ Existing servicelearning courses at pharmacy schools have significantly enhanced students' cultural awareness, communication skills, and familiarity with community wellness resources. ${ }^{14}$ The positive outcomes of implementing AACP recommendations at various pharmacy schools suggest that additional service-learning opportunities, such as internship programs, could provide a variety of benefits to pharmacy students.

In addition to promoting service-learning programs, the AACP has recommended that student pharmacists receive education on caring for underserved patients, or those who face a shortage of primary health care services due to geographic, economic, cultural, or linguistic barriers. ${ }^{16}$ Recommendations for educators include the development of course material that fosters students' cultural awareness, understanding of health disparities, and sense of social justice. ${ }^{17}$ The incorporation of cultural awareness training into pharmacy school curricula has enhanced students' cross-cultural communication skills and ability to provide effective care and resources to medically underserved patients. ${ }^{18}$ However, similar to the scarcity of service-learning programs, many pharmacy schools do not yet consistently provide students with instruction or experiences in caring for underserved populations - thus indicating a potential niche for servicefocused pharmacy internships. ${ }^{17,19}$

Finally, the concepts of population health and social determinants of health provide additional areas of exploration for pharmacy internship programs. Interventions targeting social and economic factors highlight the responsibility of health professionals - including pharmacists - to adopt a more holistic approach to patient care. ${ }^{20}$ In 2013, the Center for the Advancement of Pharmacy Education (CAPE) recommended that pharmacy curricula include instruction in population health management and the sociocultural factors that influence health outcomes. ${ }^{21}$ Some pharmacy programs offer elective courses or other opportunities for students to gain a population-based perspective of healthcare. At the University of North Carolina (UNC) Eshelman School of Pharmacy, students can explore rural and global pharmacy practice through certificate programs and experiential education. Alternatively, some institutions have implemented mandatory coursework that provides students with baseline knowledge of the roles of pharmacists in promoting public health. ${ }^{22}$ While various pharmacy institutions have incorporated population health topics into their curricula, cocurricular programs could provide student pharmacists with alternative avenues to actively address health disparities.

\section{UNC Student-Directed Practicum Experience}

In 2015, the UNC Eshelman School of Pharmacy implemented curricular transformation focused on self-directed learning, innovative thinking, and early immersion in patient care settings. ${ }^{23}$ As part of the School's commitment to experiential learning, students are encouraged to complete a "StudentDirected Practicum" (SDP) in the summer after their second year of pharmacy school. To meet the SDP requirements, students must (1) pursue an internship program, (2) complete reflective exercises regarding personal and professional development, and (3) develop goals for the experience and regularly evaluate progress towards their achievement. ${ }^{24}$ In line with the spirit of innovation that defines the new curriculum, students can also create their own SDP experience. In the fall of 2017, a group of pharmacy student leaders from the UNC Student Health Action Coalition (SHAC) conceived the idea to create an SDP for pharmacy students that aligned with the organization's commitment to community engagement and serving the underserved. Due to the paucity of pharmacy internships dually focused on ambulatory care and community service, student leaders envisioned a SHAC-specific SDP as a unique opportunity for student pharmacists to engage with medically underserved populations, provide care in outpatient settings, and strengthen their personal commitment to service.

\section{UNC Student Health Action Coalition (SHAC)}

SHAC is an interdisciplinary, student-led organization through which health professional students at UNC reach underserved patient populations. Student pharmacists who volunteer with SHAC participate in various community engagement activities, including providing free care at a student-run medical clinic and conducting health screenings at a local homeless shelter and a local church with a predominantly Spanish-speaking population. SHAC student leaders recently evaluated the efficacy of an educational texting program in improving health outcomes for the Spanish-speaking population the organization serves. ${ }^{25}$ Survey results found positive patient perceptions of the educational text messages and a significant decrease in systolic blood pressure for enrolled patients over five months. ${ }^{25}$ The findings from this study demonstrated the positive impact of SHAC services on patients' health outcomes and encouraged the 
pursuit of future initiatives to promote care for underserved patients. One such initiative, the SHAC-specific SDP, presents an immersive opportunity for student pharmacists in the realms of service-learning and community engagement. In this article, we will describe the development and implementation of the SHAC Ambulatory Care in Underserved Populations Internship, an innovative, service-oriented internship for pharmacy students.

\section{Internship Development \& Components Idea Development}

The UNC Eshelman School of Pharmacy developed a vision to become the preeminent school of pharmacy by transforming human health through innovations in education, practice, and research. Likewise, student leaders within SHAC have developed a similar vision to become the leading student-run healthcare organization through strategic innovation, thoughtful practice, and student empowerment. In pursuit of this mission, the SHAC Ambulatory Care in Underserved Populations Internship was developed to optimize student pharmacist learning through exploration of interdisciplinary collaboration in the ambulatory care of underserved populations. The vision of this internship is to foster a new understanding of the various underserved patient populations within North Carolina and to enhance student pharmacist engagement in creating patient-centered care plans. The primary intended outcome of this program was to better equip student pharmacists to identify and mitigate health disparities in underserved populations, both now and in their future careers.

\section{Personnel}

The SHAC Ambulatory Care in Underserved Populations Internship arose from the desire of current SHAC leaders to offer a unique co-curricular experience for their fellow student pharmacists. A committee of five third- and fourth-year students occupying various leadership positions in SHAC collaborated to design the internship program. The inclusion of both third- and fourth-year student developers allowed for a "layered learning" approach that prepared the rising third-year students to promote further development and sustain the program in future years. The student developers, under the guidance of a pharmacist faculty advisor, organized and implemented the various activities and volunteer experiences for the internship. The interns also had the opportunity to engage with practicing pharmacists from a variety of settings through both volunteering and didactic components of the internship. UNC faculty members facilitated school-based workshops and topic discussions. Pharmacy school alumni who previously served as SHAC leaders developed mentoring relationships with the interns.

\section{Development of Program Components}

In order to create a unique and enriching experience for the unpaid interns, the student planning committee and faculty advisor designed the internship program to include hands-on experiences, active learning, and engagement with a myriad of pharmacy mentors. In addition to enhancing the interns' personal and professional development, the student developers aimed to leverage the internship program to further the mission of SHAC by providing high-quality care to underserved community members. Thus, through various program components including volunteering, project participation, and faculty-led workshops and discussions, the interns actively furthered the SHAC mission while gaining skills and experience to guide them as future pharmacists (Table 1).

\section{Volunteer Experiences}

During the 8-week internship, interns served as volunteers at both SHAC Clinic and SHAC Outreach walk-in clinics. At the student-run SHAC Clinic, interns served as pharmacy volunteers once weekly. In this role, the interns worked collaboratively with students of other professions, including medicine, nursing, and social work, to provide interdisciplinary, team-based patient care during acute care clinic visits. The interns contributed to the medical team by determining optimal medication therapy for patients and providing counseling and telephone follow-up on prescriptions written during the visit. As volunteers with SHAC Outreach, interns provided point-of-care screenings to patients at four walk-in clinics during the internship program. Along with evaluating blood pressure and glucose and counseling patients on their results, interns facilitated the referral process to secure follow-up care for patients in need of further evaluation.

\section{Faculty Workshops}

In addition to engaging with underserved patients through volunteering experiences, the interns had the opportunity to further develop their cultural awareness and understanding of diverse patient populations through faculty-led workshops. These workshops also allowed the interns to gain knowledge and skills to enhance their professional development. In preparation for the workshops, the student developers collaborated with UNC faculty with focus areas ranging from clinical research to psychiatric pharmacy to develop materials and resources for each session. The topics of the five workshop sessions were principles of self-care, medical writing, interprofessional collaboration, rural pharmacy practice, and approaches to mental health. Each workshop involved instructional components, a hands-on skill- or knowledge-building activity, and open discussion. In addition, several of the workshops allowed the interns to explore topics in the context of providing quality care to underserved patient populations and mitigating health disparities.

\section{Mentoring Opportunities with Recent Graduates}

The interns were also able to benefit from mentorship with pharmacy residents and fourth-year pharmacy students who previously served as SHAC leaders. Through their meetings, the interns and mentors engaged in thoughtful and constructive discussion regarding additional opportunities for professional development, navigating pharmacy conferences, and applying to pharmacy residency and fellowship programs. These meetings allowed the interns the opportunity to ask questions about personal and professional development and benefit from the perspectives of experienced students and recent graduates. 


\section{Longitudinal Projects}

The interns had the option to participate in a longitudinal project during the internship experience with the potential to present their work at professional pharmacy meetings. Both interns elected to collaborate with SHAC leaders on a quality improvement initiative to enhance the patient referral system in addition to engaging in separate, smaller projects. These projects included (1) the creation of a patient-friendly resource guide of healthy fast food options, and (2) further development of the previously mentioned educational texting program for Spanishspeaking patients. Through involvement in SHAC projects, the interns were able to enhance the workflow process for patient referrals and produce tangible deliverables to promote patient care.

\section{Journal Clubs}

The internship experience included four journal club discussions designed to advance the interns' proficiency in critically evaluating literature and to further explore topics related to pharmacy practice in underserved populations. After two facultyled journal club sessions, each of the interns developed the content and led the discussion for one of the two remaining discussions. The topics covered during the internship experience included population health, social determinants of health, clinical management of diabetes, and pharmacist involvement in community-based health clinics.

\section{Off-site Experiences}

Throughout the internship, participants were encouraged to explore unique opportunities in pharmacy through participation in off-site visits designed to enhance their experiences and understanding of innovative ways pharmacists can serve their communities. The faculty advisor organized a volunteer experience through a local non-profit organization called Senior PharmAssist that allowed the interns to engage with underserved geriatric patients in Durham County, North Carolina. Through this experience, the interns gained insight into medication therapy management and Medicare drug plan counseling for the geriatric population.

\section{Presentations}

Over the course of the program, the interns were also responsible for one midpoint and one final presentation. For the midpoint presentation, each intern identified an underserved population and developed educational handouts for patients in that population as well as healthcare providers who work with that population. The midpoint presentations focused on social determinants of health, upstream factors that create barriers to care within specific populations, and strategies to mitigate health-related risk factors. For the final presentation, each intern investigated a common chronic disease state or medical condition in the context of providing care to underserved populations. Through this presentation, the interns provided thoughtful approaches on how to manage patients based on the specific economic and sociocultural barriers that drive their health outcomes. Both the midpoint and final presentations allowed the interns to develop oral communication skills and receive constructive feedback from the faculty advisor and fellow student pharmacists.

\section{Findings}

This student-directed, service-learning internship was implemented as a unique co-curricular opportunity for students in the summer of 2018. A committee consisting of SHAC student leaders and a faculty director selected two third-year pharmacy students from a pool of applicants as the inaugural cohort of interns. The program was conducted over eight weeks, during which interns spent approximately 15 to 20 hours per week engaged in educational activities, volunteering, and project development.

The interns positively contributed to patient care efforts at SHAC Clinic through their volunteering commitments, which included 62 collective hours of direct patient care and follow-up phone calls for medication management. Through volunteering at the clinic, the interns saw approximately 30 patients and contacted 12 patients via telephone over the two-month internship period. By participating in monthly SHAC Outreach screenings, the interns completed 15 hours of service and conducted hypertension and diabetes screenings for approximately 30 patients. Finally, the interns completed 5 hours of service for geriatric patients at the Senior PharmAssist site.

The advent of this internship program bolstered the volunteer presence at SHAC Clinic and Outreach screenings. While securing sufficient volunteer numbers has historically posed challenges to SHAC during summer months, the volunteering requirement of the internship promoted the sustainability of SHAC and its commitment to patient care. For example, in June-July of 2018 only four Clinic volunteer positions were left unfilled, compared to 14 unfilled positions in June-July of 2017. Similarly, only 6 Outreach positions remained open in summer 2018, compared to 16 spots the previous year. These findings suggest that by incorporating a volunteer requirement into the interns' curriculum, SHAC was able to serve a greater number of patients and improve the efficiency of Clinic and Outreach events by ensuring sufficient volunteer coverage. Ultimately, this enhanced volunteer presence translated to the delivery of higher-quality patient care for a greater number of patients.

In addition to their contributions to the patient care efforts of SHAC, the interns also benefited from opportunities to network with pharmacists in various fields. Through the faculty-led workshops and volunteer experiences, the interns interfaced with 32 pharmacists from various backgrounds. The pharmacist interactions and volunteer experiences exposed students to various types of pharmacy practice, including outpatient acute care, ambulatory care, community pharmacy, rural pharmacy, and psychiatric pharmacy. In addition, by volunteering at SHAC Clinic and participating in the interprofessional collaboration workshop, interns gained practical experience in interdisciplinary collaboration for patient care. 
In addition to professional and career-building opportunities, the interns had numerous opportunities to expand their cultural awareness by serving diverse patient populations. Although student pharmacists are likely exposed to underserved patient populations during their pharmacy practice experiences, SHAC provides a unique opportunity for interns to become more intentionally engaged with these populations and connect underserved individuals to community and health resources. The broad range of patients served included individuals experiencing homelessness, a primarily Spanish-speaking Latino/a population, geriatric patients, and uninsured or underinsured individuals, among other groups. By serving these patient populations, the interns promoted the SHAC mission of providing free, teambased, quality-driven health care and had the chance to enhance their cultural awareness and sensitivity as future health professionals.

Both formal and informal questionnaires were developed to gain the perspectives of the workshop faculty, faculty director, student developers, and interns with the goal of identifying strengths and weaknesses of the internship. Interns completed a pre- and post-survey while workshop faculty provided feedback in person or via email. This feedback was then used to facilitate a debriefing discussion between the faculty director and the student developers. Considering the small cohort of interns, these questionnaires were not validated and were used solely for the purposes of quality assurance and improvement.

Formative feedback from workshop faculty was sought following each workshop. Workshop faculty were asked about their overall experience leading the workshop, strengths and limitations with the implementation of the workshops, and their interest in partnering in the future. Overall, the workshop faculty expressed similar, positive responses. For example, several faculty members noted that the workshop structure consisting of pre-readings and application of concepts through interactive workshop sessions aligned well with the School's curricular transformation. One suggestion for improvement was for student developers to aim for a larger cohort of interns to allow for more impactful and robust workshop discussions. Each workshop faculty member welcomed the idea of continuing his or her partnership with the internship in the future.

At the close of the internship program, the student developers and faculty advisor conducted a quality improvement evaluation to promote enhancement of the experience for the future. In doing so, the development team identified notable strengths of the internship as well as opportunities for further expansion. The team agreed that the creation and implementation of the internship allowed for interns and student developers alike to benefit from expanded professional opportunities and skills. Of note, one area of improvement involves the role of student developers. Fourth-year pharmacy student developers served as mentors to the interns, while third-year pharmacy student developers worked solely on internship development. Considering that the fourth-year students were limited in their ability to attend workshops due to concurrent advanced pharmacy practice experiences, mentoring sessions generally occurred via video conference.

The interns' final reflections also provided insight into the impact of the program on their personal and professional development. The interns were encouraged to establish specific, measurable, attainable, realistic, and timely (SMART) goals prior to the experience and monitor their progress towards those goals throughout the internship program. While both interns reported that they achieved their SMART goals, they were also able to identify specific areas for further growth. For example, one intern described her success in strengthening her patient counseling skills in an ambulatory care setting. However, she also recognized an opportunity to further improve how she communicates with patients through language interpreters in the future. Additionally, both interns noted that they gained confidence in advocating for the role of the pharmacy student on an interdisciplinary healthcare team, and both plan to apply this experience to future team-based endeavors as pharmacists. When asked how the internship program impacted their career aspirations, both interns reported that this experience reinforced their interest in providing direct patient care in an ambulatory setting. Both students also expressed a desire for continued experience serving underserved patient populations throughout their pharmacy careers.

\section{Discussion}

The SHAC Ambulatory Care in Underserved Populations Internship provides a robust experience that occupies a unique space in the pharmacy internship landscape. Although many internships may include service-learning opportunities to complement their curriculum, the holistic care of underserved populations serves as the motivation behind all activities in the SHAC Internship. This experience aims to better equip student pharmacists to identify and address health disparities in underserved populations, both now and in their future careers. Interns participated in direct patient care opportunities with diverse patient populations through volunteering and off-site experiences. In addition, interns explored various aspects of serving underserved patients through workshops with faculty mentors, discussions with fourth-year students and recent graduates, and journal clubs that focused on the nuances of healthcare in diverse populations. Presentations centering on chronic disease state management in underserved populations and longitudinal quality improvement projects allowed interns to apply these themes and contribute to SHAC initiatives.

The SHAC Internship is also unique in that the experience was created by students for fellow students. SHAC student leaders identified a service-learning internship as an innovative way for student pharmacists to develop the skills needed to provide care for underserved populations. The development of program components stemmed from a discussion among SHAC student leaders about their own development of these skills through years of involvement with the organization. A student 
perspective facilitated the creation of a program that would benefit patients as well as provide efficient learning opportunities for participants. The involvement of a faculty advisor was invaluable for the further development of these ideas into a cohesive curriculum. Through this process, SHAC student leaders gained an appreciation for the work required to create educational opportunities for learners. As a result of early involvement in the design of experiential pharmacy education, SHAC student leaders will be better equipped to promote pharmacy education as practitioners in the future.

Although the internship successfully executed the mission of SHAC for the first year, various opportunities exist to enhance the experience in the future. While many program components focused on the social determinants of health that impact the care of underserved populations, more time could be dedicated to therapeutic discussions and development of advanced clinical knowledge. Additionally, daytime programming prohibited extensive in-person involvement of fourth-year mentors. To take advantage of a layered learning approach, some program components could be scheduled in the evening when fourth-year students would be available to participate. As more students participate in the internship in the future, the evaluation structure could be improved by including more objective assessments of the program components in addition to interns' reflections on their SMART goals. Finally, more emphasis could be placed on teaching interns to identify community resources to supplement the care provided at SHAC. Adopting this focus would provide interns with the skills necessary to create community networks dedicated to providing care for underserved populations in their future pharmacy endeavors.

\section{Conclusion}

The SHAC Ambulatory Care in Underserved Populations Internship is an innovative, student-developed internship that provides rising third-year student pharmacists the opportunity to engage with underserved populations in an ambulatory care setting. Through participation in longitudinal projects, workshops with faculty experts, and direct patient care experiences on an interdisciplinary team, internship participants are equipped with the skills to recognize and mitigate health disparities in their current and future pharmacy practice.
Acknowledgements: The authors would like to thank the following faculty members who served as workshop leaders for the internship and were influential in its success: Dr. Suzanne Harris, Dr. Laura Rhodes, Dr. Craig Lee, Dr. Kimberly Sanders, Christina Pomykal, and Stephanie Kiser. We would also like to thank Dr. David Steeb for his leadership and oversight managing the school-based practicums for student pharmacists. Lastly, we would like to extend our thanks to Ashlyn Norris for her monumental role as a fellow student developer and workshop leader.

\section{Conflict of Interest and Financial Disclosures: None}

\section{References}

1. Amerine LB, Valgus JM, Moore JD, et al. Implementation of a longitudinal early immersion student pharmacist health system internship program. Curr Pharm Teach Learn. 2017;9(3):421-426.

2. Clark JS. Developing the future of pharmacy through health-system pharmacy internship programs. Am J Heal Pharm. 2007;64(9):952-954.

3. Skledar SJ, Martinelli B, Wasicek K, et al. Training and recruiting future pharmacists through a hospital-based student internship program. Am J Heal Pharm. 2009;66(17):1560-1564.

4. Crouch Z. Industry internships: a different way to spend your summer vacation. Pharmacy Times. 2007.

Accessed June 1, 2018.

https://www.pharmacytimes.com/publications/career/ 2007/careers 2007-09/careers 2007-09 5089.

5. Student Vision: Internships Toolkit. Industry Pharmacists Organization website. Accessed June 1, 2018.

https://www.industrypharmacist.org/students.php.

6. Fellowships, Internships, and Learning Opportunities. Centers for Disease Control and Prevention website. Accessed June 1, 2018. https://www.cdc.gov/fellowships/shortterm/doctoral.html.

7. The Summer Internship Program at the NIH. National Institutes of Health website. Accessed June 1, 2018. https://www.training.nih.gov/trainees/summer intern s/.

8. Sullivan M, Ogurchak J. New student guide to preparing for a career in specialty pharmacy. Specialty Pharmacy Times. 2017. Accessed June 1, 2018.

https://www.specialtypharmacytimes.com/news/newstudent-guide-to-preparing-for-a-career-in-specialtypharmacy.

9. Pattin AJ, Kelling SE, Szyskowski J, et al. The redesign of a community pharmacy internship program. J Pharm Pract. 2014;29(3):224-227. 
10. UNC Health Care Pharmacy Services. UNC Health Care Clinic-Based Ambulatory Care Pharmacy Internship. Accessed June 1, 2018. https://www.uncmedicalcenter.org/app/files/public/98 20/pdf-medctr-pharmacy-clinicbasedamcarein.pdf.

11. VA Careers: Pharmacy Student Clerkships. U.S. Department of Veterans Affairs. Accessed June 1, 2018. https://www.vacareers.va.gov/studentstrainees/pharmacists.asp.

12. Peters SJ, MacKinnon GE. Introductory practice and service learning experiences in US pharmacy curricula. Am J Pharm Educ. 2004;68(1):1-5.

13. Pittenger AL, Copeland DA, Lacroix MM, et al. American Association of Colleges of Pharmacy (AACP): Report of the 2016-17 Academic Affairs Standing Committee: Entrustable Professional Activities Implementation Roadmap. Am J Pharm Educ. 2017;81(5):S4.

14. Kearney KR. Impact of a service-learning course on first-year pharmacy students' learning outcomes. Am J Pharm Educ. 2013;77(2):34.

15. Smith RE, Kerr R a., Nahata MC, et al. Engaging Communities: Academic Pharmacy Addressing Unmet Public Health Needs: Report of the 2004-05 Argus Commission. Am J Pharm Educ. 2005;69(5):S22.

16. Medically Underserved Areas and Populations (MUA/Ps). Health Resources \& Services Administration. October 2016. Accessed June 1, 2018. https://bhw.hrsa.gov/shortage-designation/muap.

17. Zweber A, Roche VF, Assemi M, et al. Curriculum recommendations of the AACP-PSSC task force on caring for the underserved. Am J Pharm Educ. 2008;72(3).

18. Assemi M, Cullander C, Hudmon KS. Implementation and Evaluation of Cultural Competency Training for Pharmacy Students. Ann Pharmacother. 2004;38(5):781-786.

19. Shaya F, Gbarayor C. The case for cultural competence in health professions education. Am J Pharm. 2006;70(6):1-6.

20. Williams D, Costa M. Moving upstream: how interventions that address the social determinants can improve health and reduce health disparities. J Public Health Manag Pract. 2008;14(Suppl):S8-17.

21. Medina MS, Plaza CM, Stowe CD, et al. Center for the Advancement of Pharmacy Education Educational Outcomes 2013. Am J Pharm Educ. 2013;77(8): Article 162.

22. Addy CL, Browne T, Blake EW, et al. Enhancing interprofessional education: Integrating public health and social work perspectives. Am J Public Health. 2015;105:S106-S108.

23. Roth MT, Mumper RJ, Singleton SF, et al. A Renaissance in Pharmacy Education at the University of North Carolina at Chapel Hill. N C Med J. 2011;49(1):48-52.

24. Personal Communication: David R. Steeb, PharmD, $\mathrm{MPH}$, email communication, July 2018.

25. Liu I, Jones $M$, Anderson S, et al. Texting and Educating on Lifestyle Therapy: A Pilot Study in a SpanishSpeaking Population in North Carolina. Journal of Student Run Clinics. 2018:1-11. 
Table 1. SHAC Ambulatory Care in Underserved Populations Internship Model: Objectives, Learning Activities, and Outcomes

\begin{tabular}{|c|c|c|}
\hline Objectives & Learning Activities & Outcomes \\
\hline $\begin{array}{l}\text { Enhance student pharmacist } \\
\text { engagement with underserved } \\
\text { patient populations } \\
\text { Bolster presence of student } \\
\text { pharmacist volunteers at SHAC } \\
\text { programs during summer } \\
\text { months } \\
\text { - } \text { Promote pharmacy practice } \\
\text { experience in ambulatory care } \\
\text { settings } \\
\text { Foster interprofessional } \\
\text { relationships through team- } \\
\text { based patient care efforts } \\
\text { Support development of } \\
\text { professionalism and } \\
\text { communication skills } \\
\text { Equip interns to identify and } \\
\text { mitigate health disparities in } \\
\text { their communities }\end{array}$ & $\begin{array}{l}\text { - } \text { Volunteering at SHAC Clinic (student- } \\
\text { - } \quad \text { Volunteering at SHAC Outreach } \\
\text { - } \quad \text { (student-run, free health screenings) } \\
\text { - } \quad \text { Mentoring sessions with recent } \\
\text { - } \quad \text { graduates } \\
\text { - } \text { Journgitudinal project development } \\
\text { - } \text { Off-site volunteering at a non-profit } \\
\text { - } \text { organization } \\
\text { Midpoint and final presentations on } \\
\text { disease state management in } \\
\text { underserved populations }\end{array}$ & $\begin{array}{l}\text { - } 60+\text { collective hours of direct } \\
\text { patient care experience with } \\
\text { underserved populations } \\
\text { - } \quad \text { 70+ patients served at SHAC Clinic } \\
\text { and SHAC Outreach } \\
\text { - Increase in student pharmacist } \\
\text { volunteer coverage at SHAC Clinic } \\
\text { and SHAC Outreach screenings } \\
\text { Development of interprofessional } \\
\text { collaboration skills in ambulatory } \\
\text { practice settings } \\
\text { Self-reported improvement in } \\
\text { patient counseling and } \\
\text { communication skills } \\
\text { Self-reported increase in } \\
\text { commitment to serving } \\
\text { underserved populations and } \\
\text { addressing health disparities }\end{array}$ \\
\hline
\end{tabular}

